\title{
Pattern Formation in Artificially Activated Ectoderm (Rana pipiens and Ambystoma punctatum)
}

\author{
P. D. NIEUWKOOP \\ Hubrecht Laboratory, Utrecht, The Netherlands
}

Accepted October 22, 1962

INTRODUCTION

The prosencephalic inductions evoked with heterogeneous inductors in explants of competent ectoderm (Toivonen and Saxén, 1955; Holtfreter, 1944; Yamada, 1950) and those evoked with denaturated archenteron roof (Rollhäuser-ter Horst, 1953; Hori and Nieuwkoop, 1955) showed rather complex anterior brain formations, of which several structures, e.g., telencephalic masses with olfactory placodes and in particular eyes, were more or less normal in appearance. These experiments indicated that even under these abnormal conditions a certain degree of self-organization is achieved in the prosencephalic neural cell material. The disaggregation and reaggregation experiments of Boterenbrood $(1958,1962)$ have demonstrated very convincingly that after the complete disturbance of the original pattern in the anterior neural plate the formation of a new pattern occurs in the reaggregated neural cells.

In order to approach pattern formation in the anterior neural plate from as many sides as possible, the author studied the neural structures formed in artificially activated ectoderm of early gastrulae of Rana pipiens and Ambystoma punctatum. The material was collected during a 3 months' stay at the Department of Zoology of the State University of Iowa in Iowa City in the spring of 1960.

\section{EXPERIMENTS}

Rana pipiens

Presumptive ectoneuroderm of late blastulae and early gastrulae of Rana pipiens (stage 9 and 10) ${ }^{1}$ was treated for about 1 hour with a

${ }^{1}$ In analogy to the corresponding stages of Xenopus laevis according to Nieuwkoop and Faber (1956). 
Ca-free Niu-Twitty solution, which caused a more or less complete disaggregation of the ectodermal cells. Subsequent transfer to a normal solution led to reaggregation of the embryonic cells into a more or less spherical cell mass. During further development the majority of the explants acquired a dumbbell shape, one side showing adhesive gland formation and the other side forming an epidermal vesicle with neural structures inside. Both thickenings were connected by a mass of atypical epidermis (See Fig. 1b).

After cultivation of the explants for about a week, the epidermal vesicle began to swell rapidly. Soon several explants "exploded," i.e., on one side the epidermis burst open and the neural structures protruded into the external medium. The exposure of the neural structures interfered with further differentiation, and soon disintegration started (see also Boterenbrood, 1962). The number of explants which could be reared until a sufficiently high level of differentiation was reached, was rather small, so that the experimental material requires further extension in order to make some of the interpretations conclusive.

In the material fixed at early stages of development, segregation into an inner compact neural cell mass, an intermediate placodal cell material of high cylindrical cells, and an outer epithelial layer was observed. This phenomenon has, however, been studied in more detail in the Ambystoma punctatum material (see following section).

The neural structures formed were of very different sizes, varying from very tiny neural masses to large complex formations. Except for the very small ones which were purely telencephalic, all neural structures consisted of a telencephalic neural cell mass-occasionally two more or less separated masses were formed-accompanied by a varying number of separate or partially fused olfactory placodes, a diencephalic neural cell mass, and an eye structure (see Fig. la and b). The latter structure consisted exclusively or for the greater part of a thick retinal layer, and in the majority of cases a small tapetal epithelium was present.

The presence or absence of the tapetal epithelium seemed to be related to the degree of evagination of the eye. In several explants the retinal mass had not evaginated at all but was protruding deeply into the central cavity of the neural vesicle. In such explants no tapetum formation occurred and the retinal mass bordered directly on the telencephalic and diencephalic neural masses (see Fig. 1a). In 

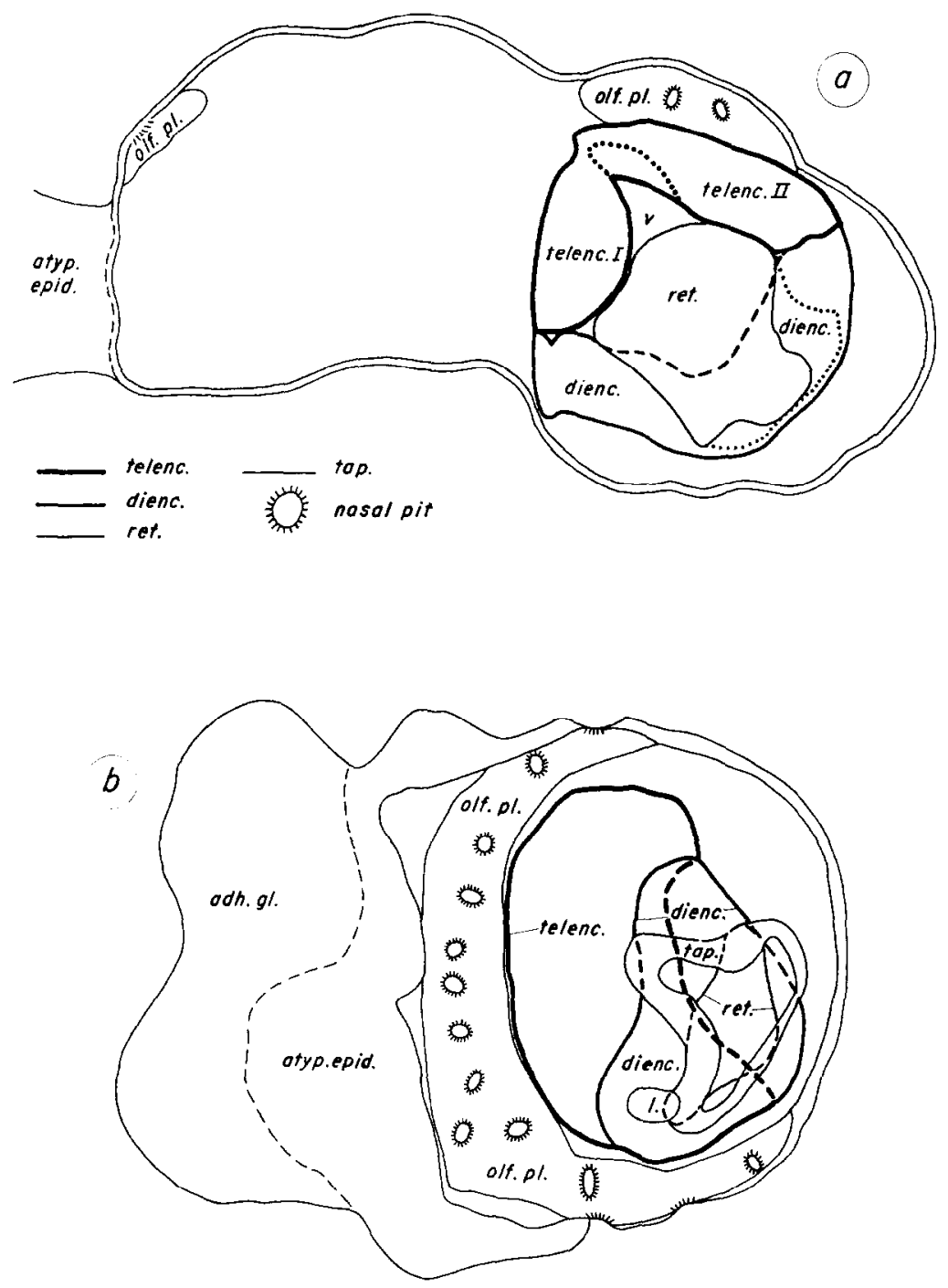

FIG. 1. Graphical reconstruction of prosencephalic neural and placodal structures in reaggregates of Rana pipiens gastrula ectoderm after cultivation for 7 days. (a) Explant Jb. (b) Explant W.

$a d h . g l$, adhesive gland; atyp. epid., atypical epidermis; dienc., diencephalon; $l$., lens; olf. $p l$., olfactory placode; ret., retina; tap., tapetum; telenc, telencephalon; v., ventricle. Continuous lines in front of, and broken lines behind, other parts. 
other explants where the eye was slightly evaginated, the retinal mass was connected with the rest of the neural formation by a narrow strip of tapetum (see Fig. Ib).

Under these conditions of cultivation no paraphysis or pineal body formation has ever been observed. The question whether this is due to the absence of neural crest cells or any other specific factor or is caused solely by a retardation of development, commonly observed in explants, cannot yet be answered.

The quantitative analysis" of the composition of the explants is given in Table 1.

TABLE 1

Absolute and Percentage Composition of Artificial

Activations in Rana pipiens ${ }^{a}$

\begin{tabular}{ccccc}
\hline $\begin{array}{c}\text { Explant } \\
\text { designation }\end{array}$ & $\%$ Telencephalic & $\%$ Diencephalic & $\%$ Eye & $\begin{array}{c}\text { Total volume } \\
\text { (p.u.) }\end{array}$ \\
\hline $\mathbf{J a}$ & 100.0 & - & - & 38 \\
$\mathrm{Nb}$ & 100.0 & - & - & 606 \\
$\mathrm{~Gb}$ & 50.5 & 15.3 & 34.2 & 924 \\
$\mathrm{Fa}$ & 100.0 & - & - & 1045 \\
$\mathrm{Fb}$ & 23.2 & 32.1 & 44.8 & 1721 \\
$\mathrm{Lb}$ & 62.2 & 16.3 & 21.5 & 5234 \\
$\mathrm{La}$ & 46.7 & 36.0 & 17.3 & 8198 \\
$\mathrm{~W}$ & 68.0 & 22.5 & 9.6 & 11920 \\
$\mathrm{Jb}$ & 62.1 & 31.5 & 5.8 & 15670 \\
$\mathrm{~V}$ & 29.6 & 41.7 & 28.7 & 18406 \\
& 45.1 & 44.1 & 10.8 & 37976 \\
\hline
\end{tabular}

a The table gives the absolute size of the total neural mass in planimetric units (1 planimetric unit, p.u., corresponds to $4 \times 10^{3} \mu^{3}$, the planimetric coefficient being 4) as well as the percentage composition in telencephalic, diencephalic, and eye anlagen. The individual explants have been arranged according to increasing total volume of the neural structures.

Although a sharp threshold value does not seem to exist-explant $\mathrm{Nb}$ shows segregation into telencephalon, diencephalon, and eye, whereas explant $\mathrm{Gb}$, which is somewhat bigger, does not show this segregation-we may conclude that below a certain minimal size

" The quantitative analysis was carried out by drawing all sections, determining the borderlines between the various structures, measuring the surface areas of the different structures in every second section, and adding the values for each of the various structures. The values obtained were then multiplied by a factor of 2 . 
the neural mass differentiates exclusively into telencephalon, whereas above this critical size a segregation into telencephalon, diencephalon, and eye anlagen always occurs. The graphic presentation of the data shows clearly that the points representing the explants with telencephalic development only, form an entirely separate group and have no relationship with the other points (see Fig. 2).

In the second group of explants, in which the neural mass has segregated into telencephalon, diencephalon, and eye, there is a significant positive correlation" $(P=0.031)$ between the total size of the neural mass and the percentage of diencephalic tissue. No correlation could be demonstrated between the total size of the neural mass and the percentage of telencephalon or eye structures. Since there are not many samples, no great value can be attached to the latter conclusion. The significant positive correlation suggests that with increasing size of the total neural mass the percentage of diencephalon increases, which may be related to a preferential formation of diencephalon in the interior of the neural mass (see Boterenbrood, 1962, reaggregates of series II).

The average composition of the second group of explants is telencephalon $48.4 \%$, diencephalon $29.9 \%$, and eye $21.6 \%$. It may be interesting to compare this composition with the composition of the "normal" prosencephalon before the onset of growth, since no growth but only differentiation occurs in explants (see Boterenbrood, 1962). The composition of the prosencephalon of a normal larva of Rana pipiens at stage 34-the earliest stage at which the bordelines between tel-, di-, and mesencephalon and eye can be determined with sufficient accuracy-is telencephalon $28.9 \%$, diencephalon $45.8 \%$, and eye $25.4 \%$. Under the present experimental conditions "artificial activations" show a high percentage of telencephalic structures and a low percentage of diencephalic structures in comparison with the corresponding value of the prosencephalon in normal development.

\section{Ambystoma punctatum}

Barth (1941) showed for the first time that the ectoderm of Ambystoma punctatum is very easily activated artificially. Rearing of isolated gastrula ectoderm in salt solution, as, e.g., Holtfreter or NiuTwitty solutions, is alone sufficient for a partial activation of the ecto-

"For testing correlations the distribution free rank-correlation method of Kendall has been used, with a level of significance of 0.05 . 
(a)

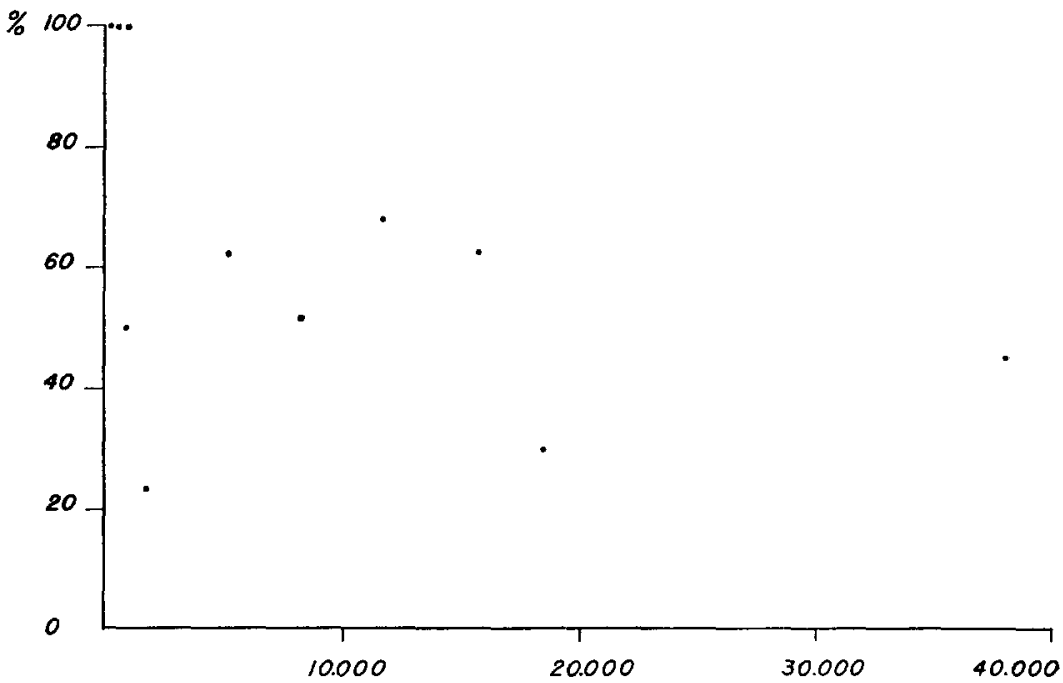

(b)

DIENCEPHALON

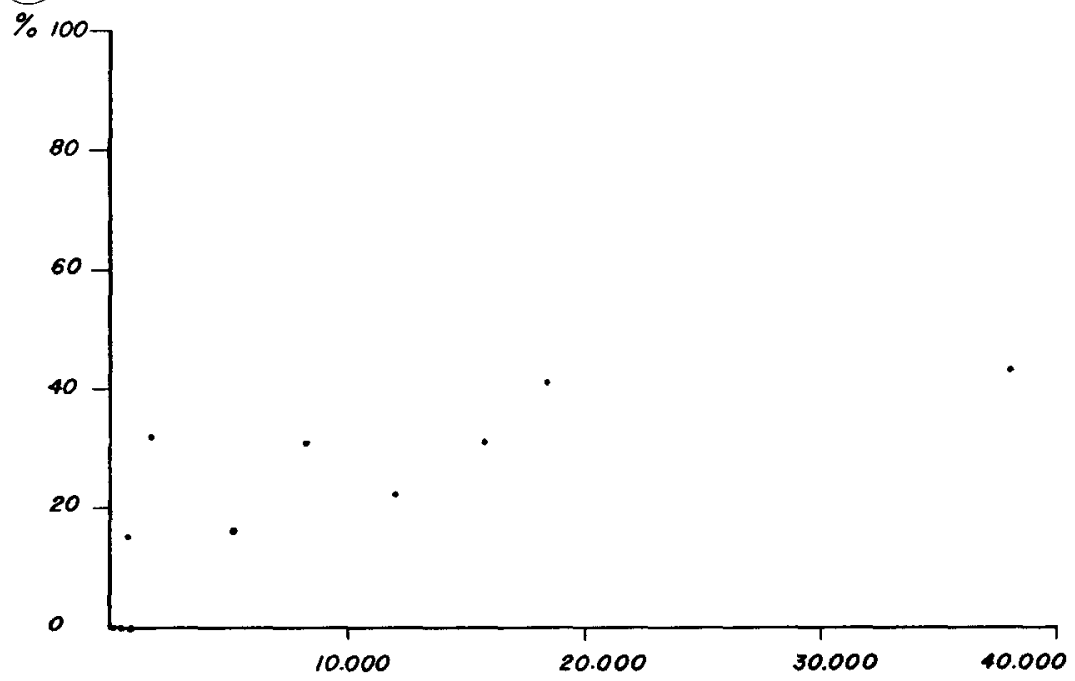




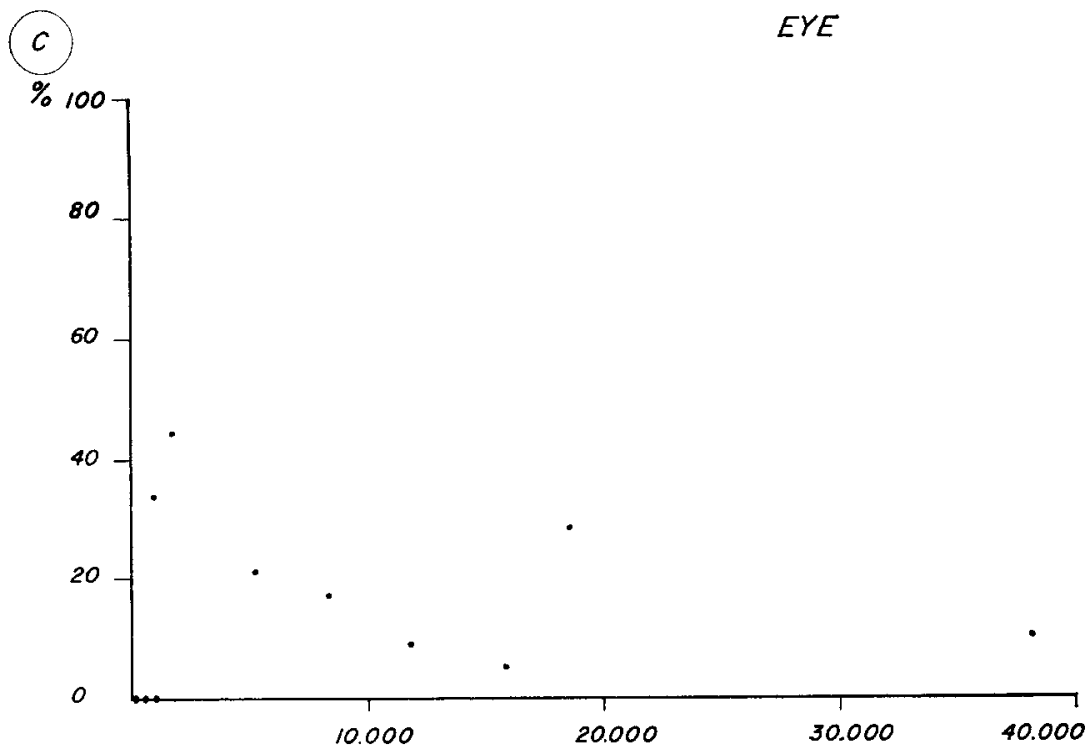

total volume in p.u.

FIg. 2. Diagrams giving relation between total volume of neural structures in planimetric units and percentage of (a) telencephalic, (b) diencephalic, and (c) eye structures in artificial activations in Rana pipiens gastrula ectoderm.

derm, so that disaggregation and reaggregation of the ectoderm is not required. In these experiments nomal Holtfreter and Niu-Twitty solutions were therefore used.

Two slightly different methods of cultivation of the isolated ectoderm have been used in these experiments. In one rather small series of experiments the presumptive ectoneurodermal caps of two early gastrulae (Harrison stage 10-101/2) were flattened on the wax bottom of the opcration dish and subsequently combined with their inner surfaces adhering to each other. The edges of both layers were trimmed until they accurately fitted each other. The nearly circular disks were reared in normal salt solution.

The wound edges along the periphery of the "double" sandwich usually first curled outward and stayed open for some time before they began to curl inward and the surface coats of both layers fused. After 1-2 days, the edge of the sandwich thickened markedly, while the 
rest of the sandwich showed epidermal folding and stretching. One or 2 days later the thickened edge of the sandwich began to contract,
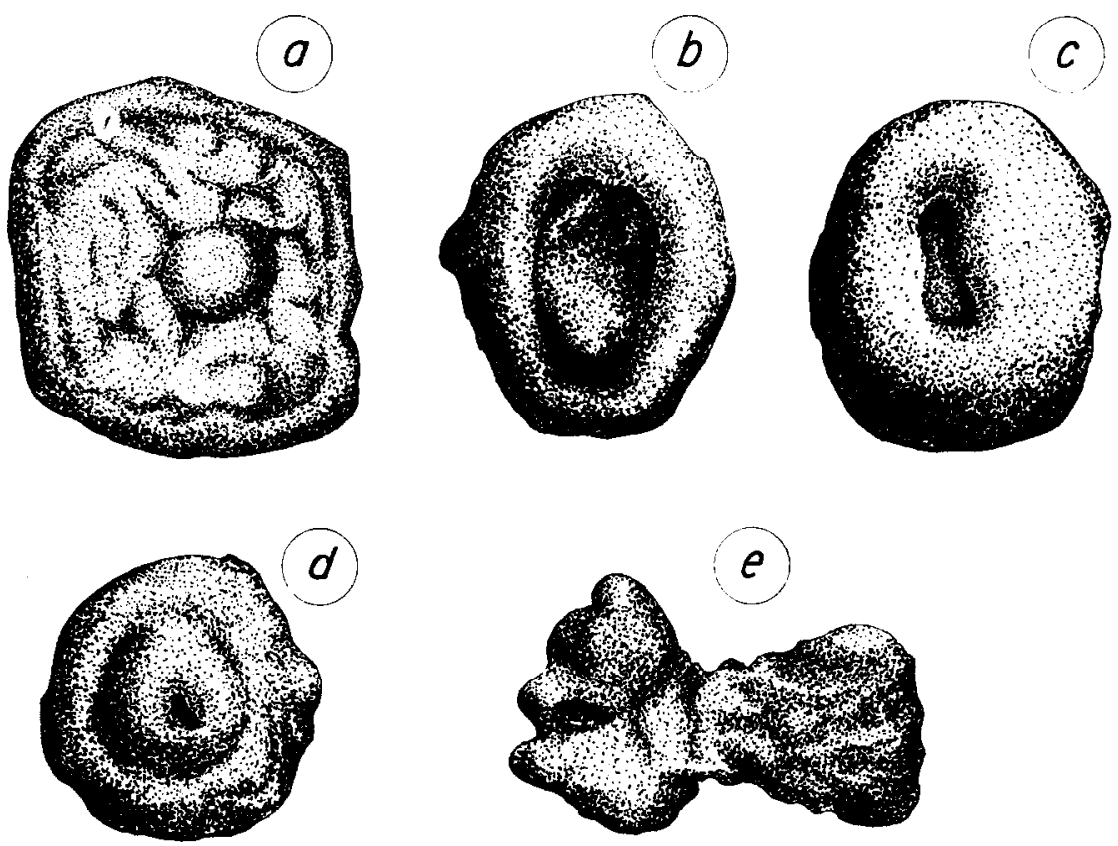

FIg. 3. External appearance of "double" sandwich of Ambystoma punctatum gastrula ectoderm no. 34 after cultivation for 24 hours (a), for about 2 days (b), for about 3 days (c), for about 4 days (d), and for about 11 days (e).

whereas the rest of the sandwich appeared to expand. The originally flat sandwich consequently changed into a cap- and later into a sacshaped structure with the thickened edge surrounding the opening (cf. Fig. 3a-d). The contraction of the thickened edge continued, so that the opening finally closed and the explant became a solid mass to which a closed ectodermal sac was attached (cf. Fig. 3e).

In the second series of experiments the presumptive ectoneurodermal cap of only one early gastrula was stretched and subsequently attached by its inner surface to a thin collodion membrane (see Nieuwkoop, 1946, part I). The ectoderm stuck firmly to the collodion mombranc with the exception of the outer edge, which usually first curled outward before curling inward; the surface coat then adhered 
to the collodion membrane. After 1-2 days, the "single" sandwich also showed a markedly thickened edge, which subsequently began to contract. The firm attachment to the collodion membrane, however, interfered with any reduction of the size of the ring-shaped thickening. The contraction now led to a gradual breaking up of the ring-
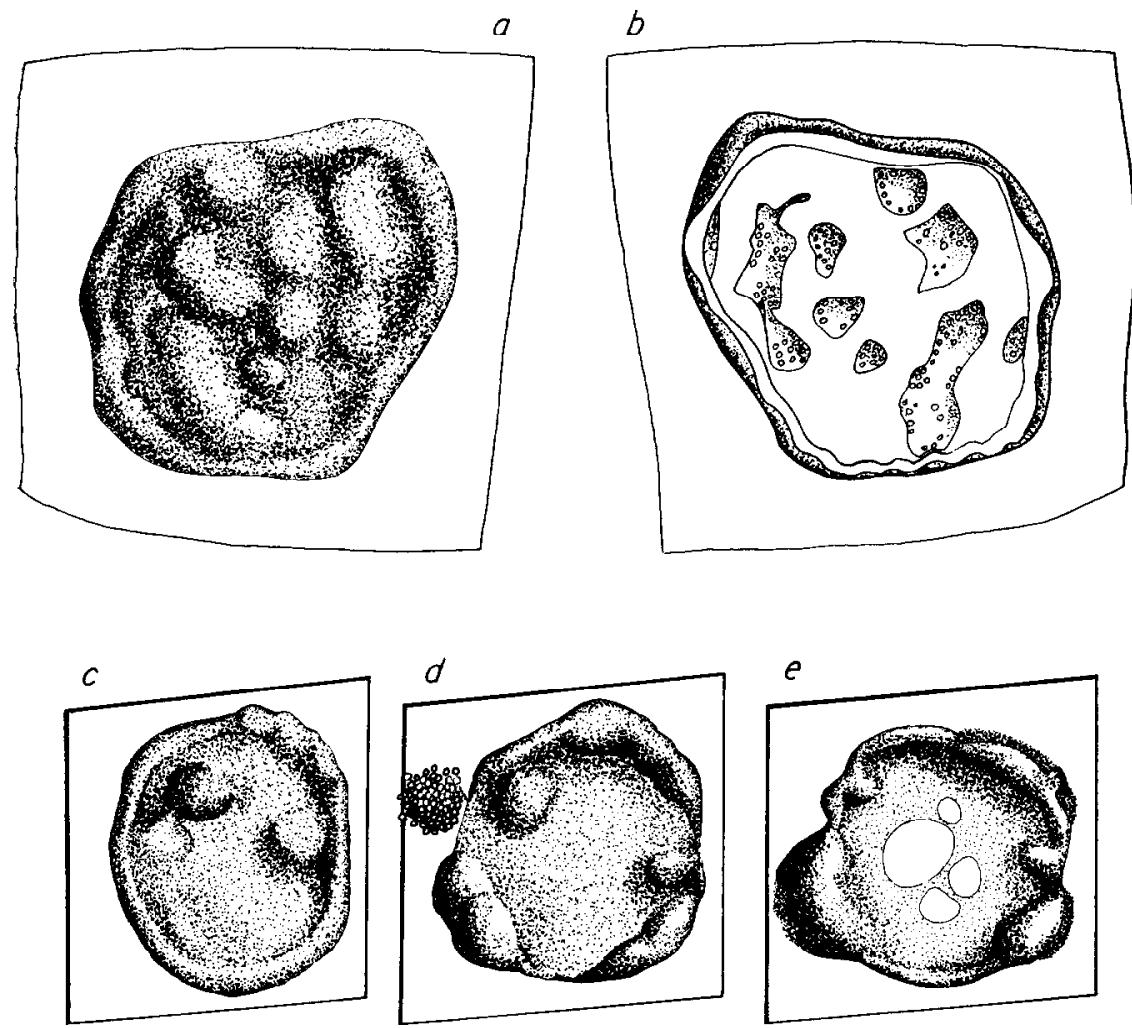

FIc. 4. External development of "single" sandwich of Ambystoma punctatum gastrula ectoderm attached to collodion membrane. (a) upper side and (b) lower side, showing firm attachment of edge of ectodermal layer to collodion membrane and formation of small cavities filled with fluid and some necrotic cells. Cultivation for 24 hours.

(c) Formation of ring-shaped activation after cultivation for 24 hours. Cavity formation under central portion of sandwich. (d) Breaking up of ring-shaped activation into separate lumps and extrusion of necrotic cells after 3 days of cultivation. (e) Thinning of central portion of sandwich and appearance of holes in thin membrane after 5 days of cultivation. 
shaped thickening into a number of separate lumps. Each lump gradually changed into a massive semispherical structure which finally began to swell up into a vesicle (see Fig. 4a-e).

Since the peripheral activation was so spectacular, it has been studied more closely in material fixed at successive stages of development.

The first, very striking, phenomenon is the gradual concentration of cells in the peripheral thickening which is mainly achieved by a gradual flow of cell material from the central portion of the sandwich toward the periphery. Consequently, the central portion of the sandwich becomes thinner and thinner and finally may consist only of a strongly flattened, transparent thin epithelium in which holes may even be formed (cf. Fig. 4e). This phenomenon will be studied further by means of time-lapse cinematography.

The second phenomenon is the gradual breaking up of the continuous ring-shaped thickening into a number of separate lumps, a phenomenon which usually occurs during the third day of cultivation. ${ }^{4}$

The third phenomenon to be distinguished is the segregation of the peripheral thickenings into three separate layers. In the center a neural cell mass is formed which is surrounded either on all sides or on all sides except the side facing the collodion membrane by two cell layers. There is an inner, homogeneous layer of high cylindrical cells, which is the thickened sensory layer of the epidermis, and an outer thin epithelial layer (cf. Fig. 5).

The fourth phenomenon is the further concentration of the thick intermediate layer in definite areas, the future placodal anlagen-here chiefly the olfactory placodes. The thickened, still homogeneous intermediate layer may be called the "placodal material." This secondary concentration of cell material in the intermediate layer coincides

${ }^{4}$ This phenomenon corresponds in time with the curling of the originally flat "double" sandwich into a sac-shaped structure.

FIG. 5. External and internal development of "single" sandwich (no. 11) of Ambystoma punctatum gastrula ectoderm after cultivation for 24 hours (a) and for 48 hours (b-d).

(a) and (b) Upper view of sandwich.

(c) Graphic reconstruction.

(d) Cross sections through sandwich at levels 1, 2, and 3, indicated in (c).

col., collodion membrane; neur. st., neural structure; pl. an., placodal anlage; pl. mat., placodal material; th. sens. l., thickened sensorial layer. 

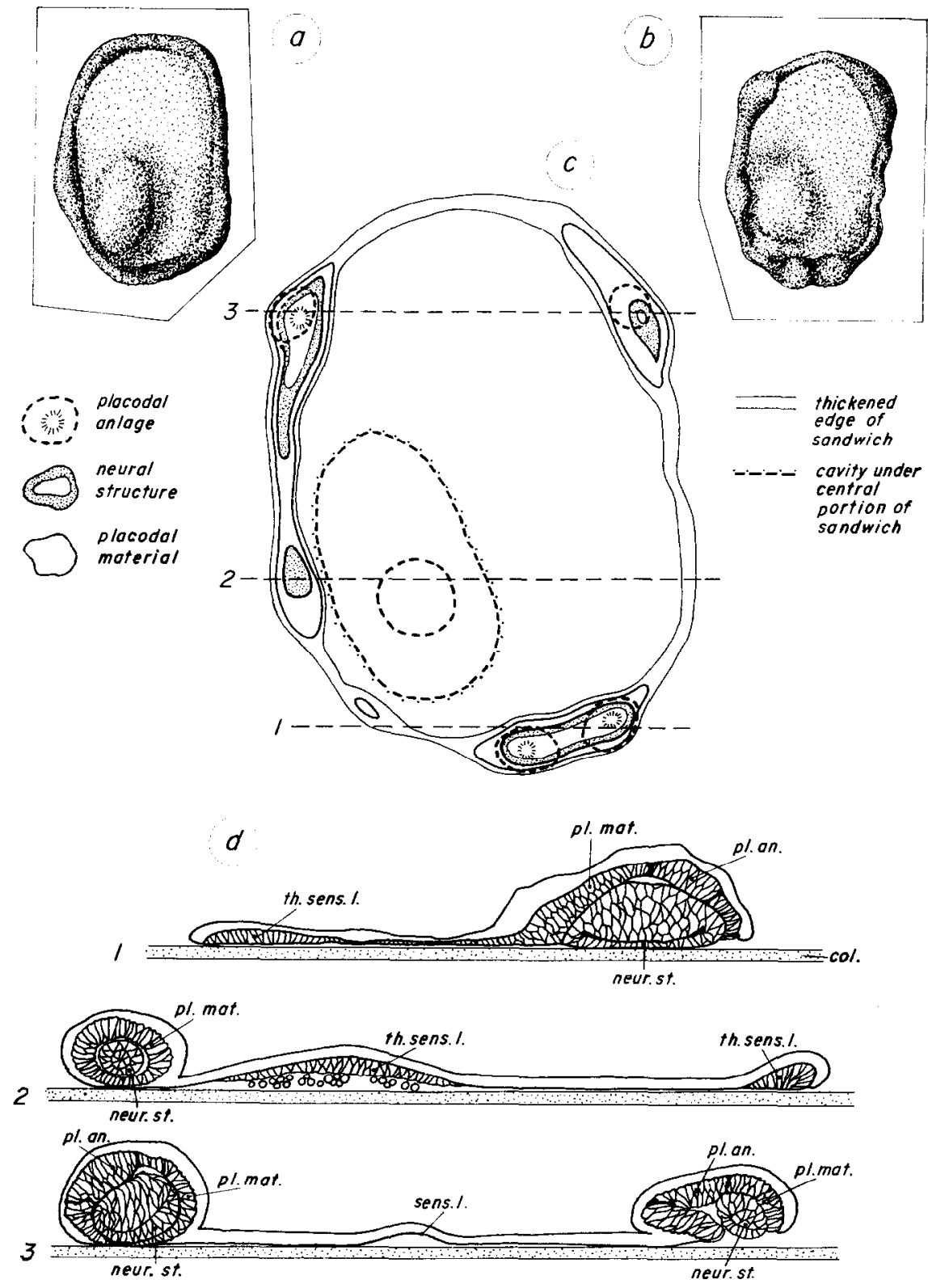
with a segregation of the central neural mass into telencephalic, diencephalic, and eye anlagen.

The last phase to be distinguished is the gradual establishment of the final organization in the telencephalic, diencephalic, and eye anlagen.

The isolated Ambystoma punctatum ectoderm frequently showed partial disintegration (see also Holtfreter, 1945). This phenomenon varied considerably from one batch of eggs to another. It was more pronounced in the "single" than in the "double" sandwiches. In some "single" sandwiches hardly any cell material accumulated in cavities formed under the ectodermal layer (cf. Fig. 4b), whereas in other explants large numbers of necrotic cells accumulated locally under the ectodermal layer and were subsequently extruded when an extending cavity reached the edge of the sandwich or simply exploded (cf. Fig. $4 \mathrm{c}$ and d). Although a thickening of the ectoderm may occasionally occur also in the central portion of the sandwich, usually after a partial or complete collapse of a blister, there seems to be no close relationship between accumulation of necrotic cell material and local activation phenomena. This point requires further analysis, and will not be considered in this article, which deals exclusively with the peripheral activation phenomenon.

In the "double" sandwiches rather large prosencephalic structures are formed. In some explants they form a single prosencephalon consisting of one telencephalon, one diencephalon, and one eye structure [nos. 34, 29 (cf. Fig. 6d), and 27]. In another explant one or two small isolated neural structures are present besides a single large one (nos. 35 and 26). In the latter specimen the large prosencephalon has a complex character. It consists of one common telencephalic mass with several olfactory placodes and two separate diencephala each associated with an eye structure. Here either incomplete segregation into two neural masses or fusion of two adjoining prosencephala seems to have taken place.

In the "single" sandwiches the individual neural masses usually segregated into a single telencephalic, a single diencephalic, and a single eye structure (cf. Fig. $6 \mathrm{~b}$ and $\mathrm{c}$ ). The smallest neural masses formed only a telencephalic structure (cf. Fig. 6a).

The quantitative analysis of the differentiated neural structures, given in Table 2, shows that with the exception of the very small ones, segregation into telencephalon, diencephalon, and eye anlagen 

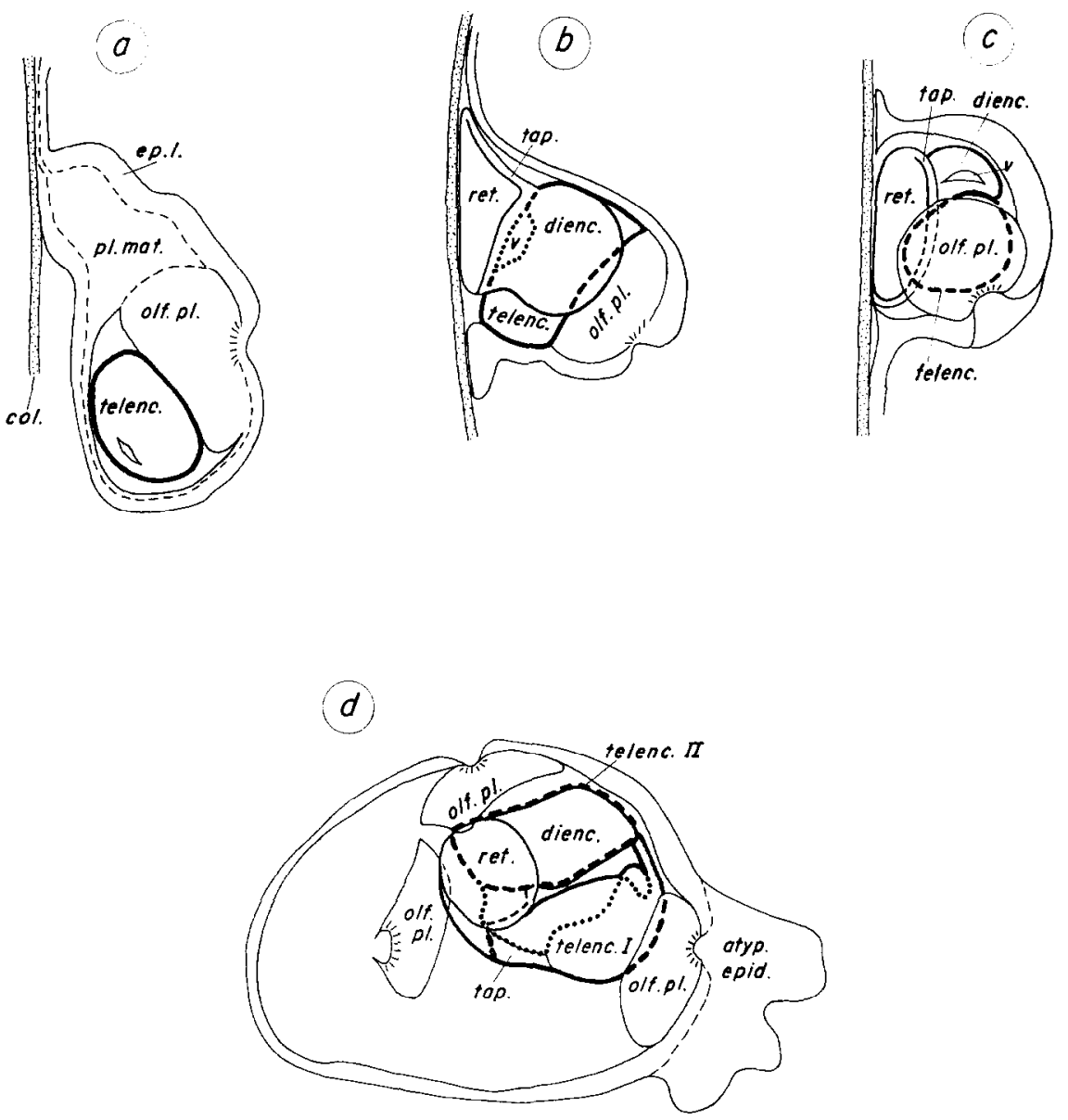

FIG. 6. Graphic reconstruction of prosencephalic neural and placodal structures in "single" sandwiches nos. 12A (a), 6c (b), and 5A (c) and in "double" sandwich no. 29 (d) of Ambystoma punctatum gastrula ectoderm. Sandwich no. $12 \mathrm{~A}$ fixed after 6 days, nos. $6 \mathrm{c}$ and $5 \mathrm{~A}$ after 10 days, and no. 29 after 13 days of cultivation.

atyp. epid., atypical epidermis; dienc., diencephalon; col., collodion membrane; ep. l., epithelial layer; olf. pl., olfactory placode; pl. mat., placodal material; ret., retina; tap., tapetum; telenc., telencephalon; $v$., ventricle.

also occurs in Ambystoma punctatum. As in Rana pipiens a certain minimal size is apparently required for this segregation process. Below this threshold a purely telencephalic differentiation takes place. 
TABIF?

Absolute and Percentage Composition of Artificial

Activations in Ambysloma punclatum*

\begin{tabular}{|c|c|c|c|c|}
\hline $\begin{array}{c}\text { Preparation } \\
\text { no. }\end{array}$ & $\%$ T'elencephalic & $\%$ Diencephalic & $\%$ Eye & $\begin{array}{c}\text { Total volume } \\
\text { (p.u.) }\end{array}$ \\
\hline $5 c$ & 100.0 & $\cdots-$ & - & 14 \\
\hline $14 \mathrm{c}$ & 100.0 & 一 & $-\cdots$ & 44 \\
\hline $5 \mathrm{Da}$ & 100.0 & 一 & - & 54 \\
\hline $35 \mathrm{C} \dagger$ & 100.0 & -- & $\longrightarrow$ & 113 \\
\hline $6 \mathrm{Ab}$ & 100.0 & - & $一$ & 194 \\
\hline $14 \mathrm{~B}$ & 100.0 & - & - & 226 \\
\hline $14 \mathrm{~A}$ & 100.0 & 一 & - & 242 \\
\hline $5 \mathrm{Db}$ & 100.0 & - & 一 & 360 \\
\hline $6 \mathrm{E}$ & 100.0 & 一 & $\longrightarrow$ & 628 \\
\hline $26 \mathrm{C} \dagger$ & 51.6 & 23.4 & 25.0 & 636 \\
\hline $35 \mathrm{~A} \dagger$ & 100.0 & $-\cdots$ & -- & 697 \\
\hline $12 \mathrm{~A}$ & 100.0 & - & - & 726 \\
\hline $5 \mathrm{E}$ & 100.0 & - & - & 750 \\
\hline $5 \mathrm{~A}$ & 43.5 & 29.8 & 26.7 & 1402 \\
\hline $39 \mathrm{~B}$ & 60.6 & 17.3 & 22.1 & 1676 \\
\hline $35 \mathrm{~B} \dagger$ & 100.0 & -- & - & 2079 \\
\hline $6 c$ & 46.7 & 14.5 & 38.8 & 2128 \\
\hline $6 \mathrm{~B}$ & 24.2 & 14.8 & 61.0 & 2482 \\
\hline $5 \mathrm{~B}$ & 36.4 & 17.1 & 46.5 & 2514 \\
\hline $6 \mathrm{D}$ & 58.9 & 30.6 & 10.6 & 2840 \\
\hline $6 \mathrm{Aa}$ & 45.2 & 20.9 & 33.9 & 2866 \\
\hline $39 \mathrm{~A}$ & 45.2 & 13.1 & 41.7 & 3106 \\
\hline $39 \mathrm{C}$ & 90.3 & 6.4 & 3.3 & 4216 \\
\hline $12 \mathrm{~B}$ & 54.3 & 32.8 & 13.2 & 4790 \\
\hline $26 \mathrm{~B} \dagger$ & 45.5 & 25.5 & 28.9 & 5876 \\
\hline $34 \dagger, \ddagger$ & 76.4 & 20.7 & 2.9 & 7025 \\
\hline $29 \dagger$ & 64.7 & 22.6 & 12.7 & 9328 \\
\hline $26 \mathrm{~A} \dagger, \S$ & 67.8 & 13.5 & 18.7 & 22878 \\
\hline $27 \dagger, \ddagger$ & 68.0 & 9.9 & 22.2 & 30036 \\
\hline
\end{tabular}

* The table gives the absolute size of the total neural mass in planimetric units ( 1 planimetric unit, p.u., corresponds to $4 \times 10^{3} \mu^{3}$, the planimetric coefficient being 4) as well as the percentage composition in telencephalic, diencephalic, and eye anlagen. The individual explants have been arranged according to increasing total volume of the neural structures.

† "Double" sandwiches.

‡ Since several sections have been damaged, the volume of the various structures could be determined only approximately.

$\S$ Here a complex neural formation consists of a large continuous telencephalon and two separate diencephalic structures, each with an eye formation. 
The graphic presentation of the data shows that the separate group of points for the small, purely telencephalic neural structures has, as in Rana pipiens, no relationship with the other points for the segregated prosencephalic structures (see Fig. 7). No significant correlation could be demonstrated between the total volume of the neural formation and the percentage of either telencephalon, diencephalon, or eye structures.

Both the "single" and the "double" sandwiches show prosencephalic structures in strongly varying quantitative proportions. The average composition of the segregated prosencephalic structures is telencephalon $55 \%$, diencephalon $19.7 \%$, and eye $25.3 \%$. When comparing these values with the corresponding values of the prosencephalon of normal larvae of Ambystoma punctatum before the onset of growth (stage 34 - -viz. telencephalon $24.8 \%$, diencephalon $41.2 \%$, and eye $34 \%$-the percentage of telencephalic structures is quite high, as it is in Rana pipiens, whereas the percentage of diencephalon is rather low.

\section{GENERAL DISCUSSION}

In the development of the peripheral activations a number of successive developmental phases can be distinguished: (1) the thickening of the edge of the sandwich by a gradual flow of cell material from the central portion of the sandwich toward the periphery of the "single" sandwich or by a general contraction of the outer zone of the freely floating "double" sandwich; (2) the breaking up of the continuous ring-shaped activation into a number of separate lumps in the "single" sandwich or the contraction of the ring-shaped activation in the "double" sandwich; (3) the segregation of the thickenings into a central neural mass, a strongly thickened sensory layer of the epidermis forming the "placodal cell material," and a thin, outer epithelial layer of the epidermis; (4) the further concentration of the "placodal cell material" into definite placodal anlagen, which takes place simultaneously with a segregation of the neural mass into telencephalon, diencephalon, and eye anlagen; and (5) the further organization of the various anlagen for the formation of more or less typical brain parts and sense organs.

In distinguishing these successive phases in the development of the artificial activations, we must be aware of the fact that each phase lasts 1 day or even longer and may therefore represent quite a complex process which may again be subdivided into separate steps. This 

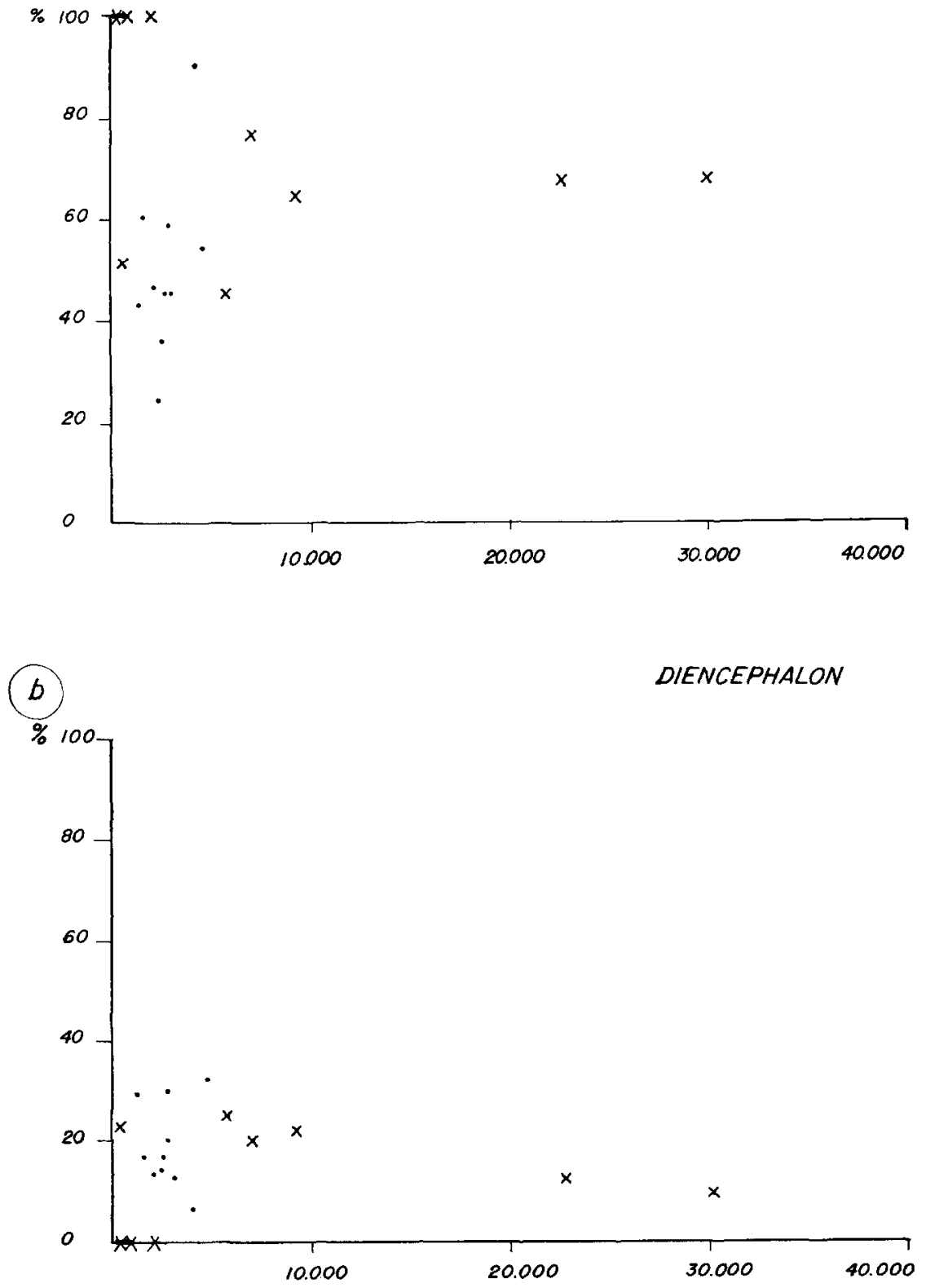


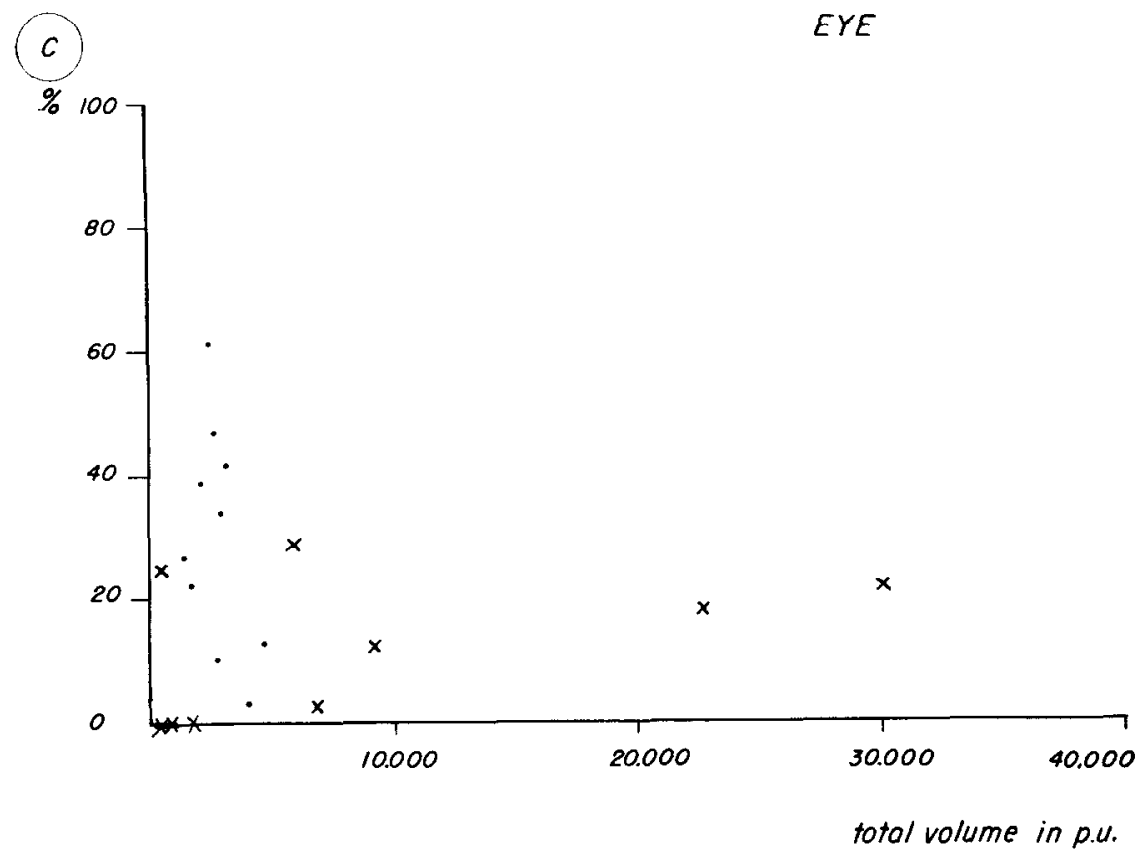

FIG. 7. Diagrams giving relation between total volume of neural structures in planimetric units and percentage of (a) telencephalic, (b) diencephalic, and (c) eye structures in artificial activations in Ambystoma punctatum gastrula ectoderm. Points $=$ "single" sandwiches; $\mathrm{x}=$ "double" sandwiches.

holds in particular for the last phase which extends over a long period of development and which will undoubtedly consist of a large number of separate phenomena which cannot yet be distinguished from each other.

The above-mentioned sequence of events strongly suggests that the segregation into "neural," "placodal" and "epidermal" cell material occurs simultaneously and represents a single process. This would mean that the formation of the placodal cell material is not caused by a secondary inductive action from the already segregated neural mass, but that the placodal cell material forms the intermediate step between epidermal and neural development in the primary induction process.

A further argument for this hypothesis is found in the discrepancy between the spatial extension of the placodal cell material which ex- 
tends over large portions of the originally ring-shaped activation ${ }^{\overline{1}}$ and the restricted areas where the neural structures become distinct (see Fig. 5c). This, however, does not form a conclusive argument since the accumulation of the neural cell material may have started earlier than the concentration of the placodal material and may already have led to a withdrawal of the neural cells from large portions of the ringshaped activation before the neural anlagen became distinct. This certainly requires further analysis.

The secondary concentration of the placodal cell material into definite placodal anlagen, which takes place simultaneously with the segregation of the prosencephalic anlagen, strongly suggests the occurrence of a secondary inductive action in the placode formation. The placode formation would therefore represent a complex process, consisting of (1) an intermediate step in the primary activation of the ectoderm, and (2) a local secondary inductive action by certain parts of the neural formation.

The observations on Rana pipiens suggest that a similar sequence of events occurs in anuran material.

In the ring-shaped activations the neural structures must have formed at the extreme periphery of the sandwich, where the activating action of the medium has been most intense. The placodal material arises in an area central to the peripheral ring of the sandwich. It is, however, likely that the activating action has not been completely uniform along the entire periphery. Although the threshold for placodal differentiation may have been surpassed along the entire periphery, neuralization may have occurred only at more favorable locations. This is exactly what has been observed during the primary segregation process.

The remarkable topography of the various cephalic and truncal placodes in normal development, i.e., in one or two rows which run parallel to and at a short distance from the periphery of the neural plate, also suggests that the placodal formations may be induced by a subliminal (subliminal with regard to neuralization) activating action causing a thickening of the sensory layer beyond the boundary of the neural anlage. Subsequent local inductive actions by certain portions of the substrate and the neural tube may be responsible for the concentration of placodal material into individual placodal anlagen.

The segregation of the neural mass shows on the onc hand some

${ }^{5}$ The ring may be locally interrupted. 
interesting general features and on the other hand a pronounced variation in quantitative composition in the individual explants.

The first striking feature is the presence of a minimal size below which no segregation into telencephalon, diencephalon, and eye anlagen occurs. This is apparently not a very sharp threshold, but shows some fluctuations both in Rana pipiens and in Ambystoma punctatum. Whether this means that first the cell material for the telencephalon is set aside before diencephalon and eye structures can be formed or, as Boterenbrood (1962) has suggested, that telencephalic differentiation is favored in the peripheral layer of the neural mass, cannot yet be settled. General conditioning factors in the morphogenesis of the telencephalic anlage, which prevent diencephalic and eye differentiation in very small masses, may also be taken into account. The observation of Sala (1956) of very small, pure eye structures in local activations-a phenomenon which has however never been reproduced-seems contradictory to these suggestions.

The second striking common feature is the constant, very simple organization of the neural structures. In nearly all explants they consist of a single telencephalic anlage associated with one olfactory placode, a single diencephalic anlage, and a single eye structure with or without a lens. This observation seems to suggest that the often very complex character of the neural formations in the reaggregates of anterior neural plate (Boterenbrood, 1962) was due to the relatively late stage of operation, so that the regional segregation of the neural material took place during the general segregation process of neural, neural crest, placodal, and epidermal cells when the neural mass was still very irregular in shape. This supposition can easily be tested experimentally.

There is a very close relationship in the Rana pipiens and Ambystoma punctatum material between telencephalic anlage and olfactory placode, a relationship which has previously been observed by several investigators and which has been studied more in detail by Haggis (1956). In the Ambystoma punctatum material the number of telencephalic units-particularly in the double sandwiches-and the number of more or less separate olfactory organs is usually nearly equal. In the Rana pipiens material, complex olfactory organs are frequently observed (e.g., in Fig. 1b).

The quantitative measurements, which are presented only in a diagrammatic form (see Fig. 8), show clearly that notwithstanding a 
pronounced individual variation-in particular in the very large structures-a highly significant correlation exists between the volume of the telencephalic structure and the volume of the corresponding olfactory $\operatorname{organ}(\mathrm{s})$. The line indicating this correlation is steeper for Ambystoma punctatum than for Rana pipiens.

The eye anlage usually consists of a large retinal mass which may or may not be surrounded by a narrow strip of tapetum epithelium. The more the eye has evaginated, the better the tapetum formation has developed. Since the evagination of the eye material is usually rather poor in these artificial activations, tapetum may be altogether lacking. In the Ambystoma punctatum material tapetum differentiation seems to occur less frequently than in the Rana pipiens material, where the majority of eye structures show at least some tapetum.

The very incomplete evagination of the eye rudiment is probably connected with the absence of neural crest cells in purely activated ectoderm (Hori and Nieuwkøop, 1955; Sala, 1956). It is still an unresolved question whether neural crest cells perform a mechanical

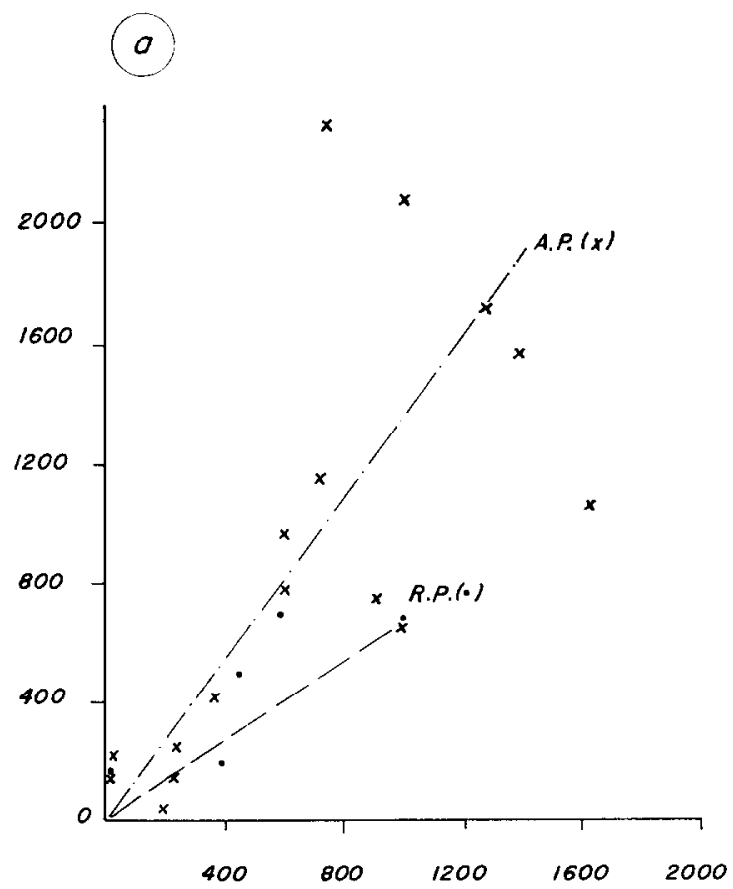




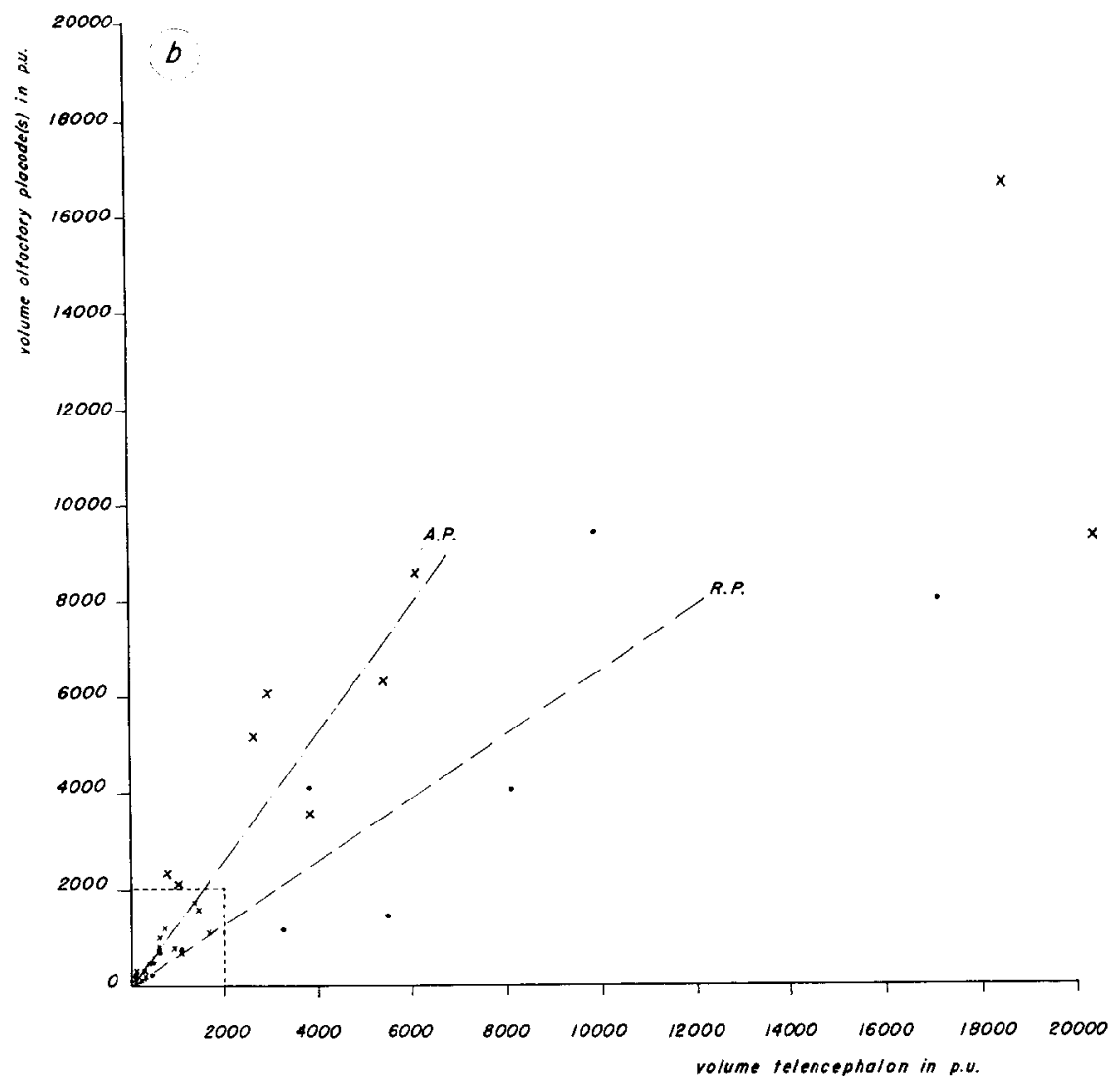

FIG. 8. Diagram giving relation between total volume of telencephalic structures in planimetric units and of corresponding olfactory placode $(s)$ in artificial activations in Rana pipiens gastrula ectoderm (points) and in Ambystoma punctatum gastrula ectoderm ( $\mathrm{x}$ ). Diagram (a) is an enlargement (5x) of part of diagram (b).

function in the evagination of the eye rudiment-since in their absence the explants remain compact during the first week of cultivation and the epidermis tightly surrounds the neural mass-or whether the neural crest exerts a more specific action. The conclusion of Lopashov (1961) that tapetum formation is conditioned by the presence of neural crest or mesodermal mesenchyme does not seem to hold in an absolute scnsc, since tapctum can apparently differentiate in the absence of neural crest. 
The pronounced variation in the quantitative composition of the artificial activations strongly suggests that pattern formation under these conditions develops in a manner similar to that suggested by Boterenbrood (1962) for pattern formation in reaggregates of anterior neural plate. According to her hypothesis, the quantitative composition depends on competition between individual centers for the remaining, still indifferent, cell material; in such competition the intensities of the individual centers play an important role. The significant positive correlation between the total volume of the neural formation and the percentage of diencephalic tissue in the Rana pipiens material supports this hypothesis. A negative correlation between the total volume of the neural formation and the percentage of telencephalic material, which was statistically significant in Boterenbrood's material, could however not be demonstrated in the Rana pipiens material. The absence of any correlation between the total volume of the neural formation and any of its component parts in the Ambystoma punctatum material may not be contradictory to the presence of a positive correlation for the diencephalon in Rana pipiens, since the spatial configuration of the activations is markedly different in the two groups of experiments. In the Rana pipiens material the activation may have had a more or less spherical form, whereas in the Ambystoma punctatum material segregation may have taken place in a ring-shaped activation, where entirely different relations between surface area and volume exist.

One must be very prudent when comparing the quantitative composition of reaggregates made from the prosencephalic region of the neural plate with artificial activations of gastrula ectoderm. Besides the difference, already mentioned, in conditions for segregation, one has to account for additional weak transforming actions in the anterior neural plate. There is nevertheless a striking difference between the average quantitative composition in the reaggregates of Boterenbrood's Triturus alpestris material and the Rana pipiens and Ambystoma punctatum material presented above. The Triturus alpestris. material showed a dominance of eye structures, whereas in the Rana pipiens and Ambystoma punctatum material the telencephalon sccms to dominate. Whether this has only to be ascribed to species-specific differences or may be based upon the character of the experiments. cannot yet be answered and requires further experimental analysis. Neither can a satisfactory explanation be given for the differences: 
between the quantitative composition of the artificial activations and that of the normal brain before the onset of growth.

\section{SUMMARY}

Presumptive ectoneuroderm of late blastulae or early gastrulae of Rana pipiens was partially activated by short-lasting disaggregation in Ca-free Holtfreter or Niu-Twitty solutions and subsequent reaggregation in normal solutions. The explants usually became dumbbell shaped and consisted respectively of an adhesive gland portion, a connecting mass of atypical epidermis, and an epidermal vesicle with neural structures. The very susceptible ectoneuroderm of early gastrulae of Ambystoma punctatum could be partially activated by simply rearing the explants in normal Holtfreter or Niu-Twitty solution. "Double" sandwiches obtained after adhesion of the inner surfaces of the flattened ectoneurodermal caps of two early gastrulae, as well as "single" sandwiches formed after the adhesion of a single flattened ectoneurodermal cap to a collodion membrane, formed very regular ring-shaped peripheral activations.

These activations segregated first into a central neural mass, an intermediate strongly thickened sensory layer, which may be called the "placodal cell material," and an outer thin epithelial layer of the ectoderm. Subsequently the placodal material concentrated in definite placodal anlagen while the neural mass segregated into telencephalic, diencephalic, and eye anlagen. This sequence of events strongly suggests that the formation of the "placodal cell material" represents an intermediate step between "neural" and "epidermal" development in the primary activation process. The subsequent concentration of this placodal material in definite placodal anlagen suggests a local secondary inductive action from certain parts of the neural formation.

The experimental material shows that a minimal size of the neural mass is required for segregation into telencephalic, diencephalic, and eye anlagen. Below this minimal size only a telencephalic anlage is formed.

The artificial activations show a very simple pattern of organization. They usually segregate into a single telencephalic anlage accompanied by a single olfactory placode (although in the Rana pipiens material complex olfactory organs are also formed) a single diencephalic anlage, and a single eye rudiment.

The quantitative composition of the segregated prosencephalic 
formation shows a pronounced variation. The telencephalic anlage seems to be dominant in the Rana pipiens as well as the Ambystoma punctatum material. The pattern formation in the artificial activations seems to agree with the hypothesis put forward by Boterenbrood (1962) for pattern formation in reaggregates of anterior neural plate.

There exists a highly significant positive correlation between the total volume of the telencephalic anlage and the volume of the accompanying olfactory placodes.

The very incomplete evagination of the eye rudiment, which is accompanied by a poor development of the tapetum epithelium, may be due to the absence of neural crest cells in the artificial activations.

The author wishes to express his gratitude to the Cultural Division of the North Atlantic Treaty Organization for financial support; to Dr. J. J. Kollros for great hospitality at the Department of Zoology; and to Dr. W. W. Ballard for collecting very early stages of Ambystoma punctatum and for the very quick shipment of this material to Iowa City.

\section{REFERENCES}

Barth, L. G. (1941). Neural differentiation without organizer. J. Exptl. Zool. 87, 371-384.

Boterenbrood, E. C. (1958). Organization in aggregates of anterior neural plate cells of Triturus alpestris. Koninkl. Ned. Akad. Wetenschap. Proc. Ser. C 61, $470-481$.

Boterensmood, E. C. (1962). On pattern formation in the prosencephalon; an investigation on disaggregated and reaggregated presumptive prosencephalic material of neurulae of Triturus alpestris. Ph.D. Thesis, Univ. of Utrecht.

HAGGIS, J. (1956). Analysis of the determination of the olfactory placode in Amblystoma punctatum. J. Embryol. Exptl. Morphol. 4, 120-138.

Holtfreter, J. (1944). Neural differentiation of ectoderm through exposure to saline solution. J. Exptl. Zool. 95, 307-343.

Holtfreter, J. (1945). Neuralization and epidermization of gastrula ectoderm. J. Exptl. Zool. 98, 161-209.

Heri, R., and NieuwKoop, P. D. (1955). Induction phenomena with denaturated inductor. Koninkl. Ned. Akad. Wetenschap. Proc. Ser. C 58, 262-272.

Lorashov, G. V. (1961). The development of the vertebrate cye in relation to the problem of embryonic induction. Ann. Zool. Soc. Zool. Botan. Fennicae Vanamo 22, 1-17.

Nieuwkoop, P. D. (1946). Experimental investigations on the origin and the determination of the germ cells, and on the development of the lateral plates and germ ridges in Urodeles. Arch. néerl. zool. 8, 1-205.

Nieuwkoop, P. D., and Faber, J. (1956). Normal table of Xenopus laevis (Daudin). North-Holland Publishing Company, Amsterdam.

Nieuwkoop, P. D., Oikawa, I., and Boddingius, J. (1958). The anterior transverse neural fold in amphibians. Arch. néerl. zool. 13, Suppl., 167-184. 
ROLLhÄUSER-ter HoRST, J. (1953). Die Induktionsleistung verschiedener TritonKeimteile nach Denaturierung. Wilhelm. Roux' Arch. Entwicklungsmech. Organ. 146, 183-200.

SALA, M. (1956). The character of the "local activations" formed in sandwich experiments of competent ectoderm containing neural formations induced by different cranio-caudal portions of the archenteron roof. Konikl. Ned. Akad. Wetenschap. Proc. Ser. C 59, 661-667.

Torvonen, S., and Saxén, L. (1955). The simultaneous inducing action of liver and bone-marrow of the guinea pig in implantation and explantation experiments with embryos of Triturus. Exptl. Cell Research, Suppl. 3, 346-357.

YAMADA, T. (1950). Regional differentiation of the isolated ectoderm of the Triturus gastrula induced through a protein extract. Embryologia I, 1-20. 